\title{
Práticas educativas: Perspectivas que se abrem para a Educação Especial*
}

\author{
Anna Maria Lunardi Padilha
}

RESUMO: O objetivo desse texto é registrar reflexões que permitam uma maior compreensão do conceito de simbolização para introduzir a questão da constituição do sujeito simbólico, comprometido pela deficiência mental. As reflexões passam por encontros com diferentes autores, de áreas diversas do conhecimento, com a intenção de marcar a escolha da perspectiva histórico-cultural como a que melhor responde às interrogações sobre o ser humano capaz de dar significado ao mundo, mesmo quando impedido por problemas orgânicos. São fundamentais as contribuições de Vigotski e Bakhtin que concebem o homem como ser que significa e se constitui nas relações concretas de vida.

Palavras-chave: Deficiência mental, sujeito simbólico, semiótica, práticas educativas

\section{Introdução}

Este trabalho revela a minha intenção de estudo: como pôr na cultura, na capacidade de significar o mundo (os objetos, as pessoas e as palavras) e na história de vida social, a vida do sujeito deficiente mental. É vislumbrar a possibilidade de empurrar a barra que separa o nor-

\footnotetext{
* Este texto refere-se à pesquisa que resultou na tese de doutorado, orientada pelo Prof. Dr. Angel Pino e co-orientada pela prof ${ }^{\mathrm{a}}$ Dra. Maria Irma Hadler Coudry.

** Doutora em Educação pela Unicamp. Professora da Universidade de Franca.
} 
mal do patológico, reconhecendo que as transformações acontecem nas relações concretas de vida e somente nelas. Relações sociais que pressupõem necessariamente as vidas envolvidas nelas.

Meus encontros semanais com Bianca, a jovem deficiente mental, que aconteceram durante três anos (do início de 1997 até o final de 1999) são descritos e analisados, levando em conta como fundamental, como essencial, como princípio, o processo de simbolização na constituição da subjetividade e, de modo particular e especial, a constituição da subjetividade do sujeito comprometido pela deficiência mental. A tentativa é de compreender o desenvolvimento desse sujeito simbólico, cultural e histórico, representado pela jovem Bianca, que nasceu com agenesia parcial do corpo caloso e diminuição do hemisfério esquerdo e que se encontrava seriamente comprometida em seu desenvolvimento cognitivo.

A opção teórica é pela perspectiva histórico-cultural do desenvolvimento humano e suas implicações metodológicas de pesquisa, apoiandome nas reflexões de Lev Semionovich Vigotski [1896-1934], e seus seguidores; na posição marcadamente dialógica da interação humana de Mikhail Bakhtin [1895-1975], que leva em conta os processos de significação, os movimentos de sentido e seu papel constitutivo do pensamento, da ação e da palavra; nas contribuições da neurolingüística, como é desenvolvida nesta universidade, orientada discursivamente para a análise dos fatos patológicos, assumindo a teoria enunciativo-discursiva da linguagem. ${ }^{1}$

O estudo de caso em uma investigação longitudinal possibilitou registrar e interpretar aspectos da esfera do simbólico: o gesto - como possibilidade de dar sentido às práticas discursivas; a narrativa; a dramatização; o desenho; a participação em jogos e o uso significativo dos objetos culturais - olhar para as práticas discursivas que relacionam cultura, cognição e linguagem.

Nessa investigação, o viver junto os conflitos da história de vida. Viver junto que precisou do olhar para os detalhes do fazer-se, captando o quase imperceptível através da microanálise. Olhar que implicou a participação da pesquisadora como elemento fundante da relação. Participação que exigiu que o registro e a análise tomassem como possibilidade interpretativa as atividades significativas de linguagem. Possibilidade interpretativa que se delineou a partir da dimensão histórico-cultural do desenvolvimento humano como opção teórico-metodológica - ou seja tomar as ações e palavras, as relações sociais, em seu movimento, estudando os fatos historicamente, que é exigência do método dialético. 
A relação normal/patológico depende de uma série de fatores que devem ser considerados e discutidos. Não somos sempre uma dessas categorias. Toda vez que ignoramos ou descartamos a dimensão histórica das definições, das determinações, dos diagnósticos, tanto melhor para aqueles que detêm o poder sobre o status quo e tanto pior para os que desejam compreender as possibilidades de desenvolvimento humano.

Georges Canguilhem, fazendo um exame crítico de tais conceitos afirma que a vida é normativa, institui normas: "a vida não é indiferente às condições nas quais ela é possível [...] a vida é de fato uma atividade normativa" (1995, p. 96). Deste ponto de vista, não existe o normal ou o patológico em si mesmos, mas exprimem, tanto um quanto o outro, outra lógica, suportável ou não. O patológico não seria, portanto, ausência de norma, mas uma outra norma, diferente das que foram inventadas pelo gênero humano, como gênero exemplar de vida.

É possível dizer, a partir deste estudo, que alguns aspectos do desenvolvimento que do ponto de vista neurológico anunciam deficiência mental e limitações podem ser superados, mesmo que tais superações possam apenas ser demonstradas em alguns níveis, por que por mim delimitados esses aspectos e captados esses níveis, num tempo também delimitado.

Algumas indagações me acompanharam: como a participação na cultura orienta e re-orienta certas atividades que não faziam parte da vida do sujeito? Como é possível introduzir novos modos de participação cultural na vida desta jovem, que desde muito nova carrega a marca de deficiente mental grave? Como o signo organiza, altera e dá outra dinâmica às redes neuronais?

O caminho percorrido mostra a evidência de que tudo ocorre numa relação discursiva, com o uso de instrumentos simbólicos cuja função é serem constitutivos do sujeito. Não há limitação previsível de incorporação cultural. Tudo o que envolve o homem é humano, é social, é cultural, com limites desconhecidos. O que não sabemos, muitas vezes, é o que fazer com as condições biológicas limitadas a partir de uma possibilidade ilimitada da dimensão cultural. Possibilidade ilimitada que se depara com muitas dificuldades no campo do simbólico, em casos de lesão cerebral.

O que pude captar sobre o desenvolvimento de Bianca quando do período da avaliação pedagógica, revelou-me que ela se apresentava com uma insuficiente densidade expressiva, e por isso sem gestos significativos, interpretáveis - um ator ainda em princípio de carreira, com 
pouco ensaio do simbólico, ainda que um ser humano social, histórico e simbólico. O corpo, vítima dos problemas neurológicos que tem, atrapalhava a entrada dela no mundo do simbólico: sua família, suas professoras, os outros adultos e crianças de seu meio não se faziam entender por ela e pouco entendiam dela. Se as possibilidades de produção e interpretação de signos não têm limites, há limitações na nossa compreensão, nos recursos disponíveis, nos conhecimentos - tão incipientes ainda...

O estudo refere-se às possibilidades de "mudanças de olhar" para as práticas educativas com sujeitos cérebro-lesados, com comprometimentos sérios no desenvolvimento mental, considerando as relações e a mútua constituição entre investigador e sujeito da investigação, entre aquele que ensina e aquele que aprende.

As possibilidades infindáveis de Bianca estavam apagadas (mas com marcas), escondidas (mas com indícios de presença), desordenadas (mas com possibilidades de organização), incompletas (mas tudo é incompletude!), obstruídas (mas com brechas para quem quiser ver e nelas entrar e nelas criar) e limitadas (porque condição inerente aos seres inconclusos...).

\section{Sobre a constituição do sujeito simbólico}

O funcionamento simbólico não tem sido privilegiado nos programas das escolas ou nas instituições de educação especial. De sujeito que se insere na cultura, dela participa, não se fala nos documentos oficiais sobre diagnóstico da deficiência. De doença e de diagnóstico fala-se muito e de forma muitas vezes equivocada.

Sem cada uma das vidas entrelaçadas, depois e a partir de nosso primeiro encontro, não haveria uma Bianca que fala, que pede, que negocia seus direitos, que interpreta e se faz interpretar, que usa gestos, que narra, que joga, que brinca, que estuda, da forma como faz, mesmo sendo deficiente.

Sem o encontro destas duas vidas e de outras que vão se juntando à nossa, não haveria uma pesquisadora mais humana, mais preparada para a luta em seu campo de trabalho, mais próxima dos deficientes e de suas vidas, com uma compreensão melhor da família deles. Nem uma pessoa mais inconformada com os diagnósticos com base em testes que 
dizem medir a inteligência e a capacidade de pensar; com o que se tem proposto nas escolas especiais (com algumas exceções). Sem este encontro, eu ficaria devendo alguns conhecimentos sobre os processos cognitivos mediados pelos processos de simbolização na constituição do sujeito.

A busca da compreensão do homem simbólico é antiga - perguntas que o homem faz sobre si e sobre o mundo acompanham o homem desde tempos ainda não bem calculados. O desejo de compreender 0 que nos assemelha e o que nos diferencia dos animais tem perpassado os estudos sobre desenvolvimento humano. São explicações diferentes que buscam esclarecer a natureza do homem e sua diferença em relação aos animais. Mesmo partindo de pressupostos não coincidentes, a maioria dos estudos concorda num ponto - cultural é diferente de natural; o homem é um animal, mas um animal de "outra" espécie: ele é capaz de criar meios extrabiológicos.

Alexis Leontiev (1904-1979), neuropsicólogo russo, estudioso da cultura e da personalidade humana com base na matriz materialista dialética e histórica de Engels e Marx, fala sobre a hominização, insistindo que são as leis sócio-históricas que dirigem o desenvolvimento do homem, depois que este se libertou da dependência anterior das leis biológicas. Com isto, não quer dizer que o homem não é mais um ser biológico - ele é um ser biologicamente cultural ou culturalmente biológico.

Neste ponto, é interessante trazer a questão do uso dos instrumentos como ponto distintivo do homem e do animal. O uso criativo dos objetos da natureza e a criação deles transformam o homem - ao mesmo tempo que a produção progride com o trabalho e a linguagem, desenvolve-se a cultura humana com todo seu simbolismo: a linguagem, as artes, as ciências, a religião...

Nem sempre o que foi dito sobre o processo de simbolização quis dizer a mesma coisa pois, como os estudos sobre o humano são mais antigos do que as chamadas ciências humanas, as investigações realizaram-se de diferentes maneiras através dos tempos e em diferentes espaços.

No nosso século, podemos dizer que foram importantes as contribuições da fenomenologia, por nos permitir estudar as realidades diferenciando-as e garantindo a existência e a especificidade de seus objetos. Importantes também as contribuições do estruturalismo. A idéia de estrutura foi fundamental para as mudanças nos modos de conceber a cultura: não mais estabelecendo níveis culturais, tais como inferiores ou superiores, mas como forma de organizar as relações sociais - estruturas culturais. 
Foi o marxismo que permitiu compreender a produção social das condições objetivas dos fatos humanos. Graças ao marxismo, é possível compreender as mudanças, as transformações sociais e pessoais como lentos processos sociais, econômicos e políticos; como resultado das contradições, lutas e conflitos sócio-políticos. Os fatos humanos são historicamente determinados e possuem leis próprias. É nessa perspectiva que desejo interpretar os fatos e construir o caminho de análise da constituição simbólica de Bianca.

O encontro com autores que tomam a matriz marxista como referência indica-me a busca do próprio Marx. Um dos pontos cruciais é o que ele fala sobre o trabalho - processo de comunhão homem/natureza, processo de criação de instrumentos culturais, portanto, processo simbólico, semiótico: “(...) Atuando assim sobre a natureza externa e modificando-a, ao mesmo tempo [o homem] modifica sua própria natureza. Desenvolve as potencialidades nela adormecidas e submete ao seu domínio o jogo das forças naturais" (1989, p. 202).

Henri Wallon (1986), que definiu seu método de trabalho como sendo o do materialismo dialético, assume que o progresso intelectual do ser humano acontece com o desenvolvimento da função simbólica. A passagem do ato motor (inteligência sensório-motora), para esta outra forma de inteligência (do plano simbólico), supõe a vida social - um meio humano - em que a linguagem e a emoção desempenham papel constituidor.

Angel Pino, nesta mesma linha de pensamento, diz que esse meio humano supõe um universo cultural entendido como "o meio próprio dos homens, construído por eles ao longo da história. Um meio feito de produções simbólicas - onde as próprias realidades naturais adquirem significação ou valor simbólico (...)" (1993, p.10).

Para Vigotski, conhecer o homem, estudar sua vida psíquica, era fundamentalmente estudar este homem em suas relações concretas de vida, adotando como método o materialismo dialético histórico. As relações concretas de vida acontecem nas práticas discursivas - ações humanas integradas em ações significativas.

É justamente na questão do caráter mediado dos processos psíquicos, elemento-chave da teoria de Vigotski, que encontro subsídios para compreender, sob seu ponto de vista, como se constitui o sujeito simbólico. Por analogia com os "instrumentos" de que fala Engels, Vigotski diz da criação dos modos de domínio das ações hu- 
manas, chamando-as de "ferramentas ou instrumentos psicológicos""dispositivos sociais e não orgânicos ou individuais" (1996, p. 93).

Vigotski, neste mesmo texto, cita exemplos destes instrumentos psicológicos: a linguagem, o sistema de numeração e o cálculo, as estratégias mnemônicas, a álgebra, as produções artísticas, a escrita, os diagramas, os mapas, os desenhos e todos os signos estabelecidos por convenção. ${ }^{2} \mathrm{O}$ fato de o homem ter criado (e criar) estas ferramentas psicológicas, estes signos, significa forma especificamente humana de ser.

Não há dúvidas de que pensar a significação é pensar o fazerse homem - hominizar-se; o que, de acordo com a perspectiva histórico-cultural, só é possível com os outros homens, ou seja, a essência do processo de desenvolvimento cultural consiste exatamente na apropriação/domínio ${ }^{3}$ do social: "toda função psicológica superior foi externa; isto significa que ela foi social; antes de se tornar uma função, foi a relação social entre duas pessoas" (Vygotsky 1989, p. 56).

Vigotski, em suas anotações sobre a Psicologia Concreta do Homem, marca as bases para a compreensão do simbólico: os signos são os mediadores das relações entre os homens, relações estas que constituem esses homens; o uso de signos marca o ser social dos indivíduos e a palavra é o signo por excelência. Foi no significado das palavras que Vigotski (1993) encontrou a unidade de análise do pensamento e da fala. Para ele, uma palavra sem significado é um som vazio. No entanto, o significado não é considerado algo pronto, acabado, imutável, mas, pelo contrário, "o significado das palavras evolui", transforma-se, altera-se, também nas relações concretas de vida social.

Mikhail Bakhtin, filósofo da linguagem, trabalha a palavra como fenômeno ideológico e instrumento semiótico por excelência. Este autor atribui força à palavra de forma a assumir que ela constitui e significa o mundo, como ele nos diz (1992a):

(...) a palavra penetra literalmente em todas as relações entre indivíduos, nas relações de colaboração, nas de base ideológica, nos encontros furtuitos da vida cotidiana, nas relações de caráter político, etc. As palavras são tecidas a partir de uma multidão de fios ideológicos e servem de trama a todas as relações sociais em todos os domínios. (p. 41) 
A palavra, signo por excelência, ganha sentido com o outro ser humano. Impregnada de história, a palavra adquire sentido contextualizado, situado historicamente. Bakhtin enfatiza a importância da natureza social do signo, em particular da palavra enunciada e de como esta enunciação desdobra-se dialogicamente. Partindo da concepção de que não há nada só individual, as categorias tais como espaço, tempo, causalidade, estão sendo construídas socialmente - a história se faz pelos homens - "todo signo, inclusive o da individualidade, é social" (Ibidem, p. 59).

\section{A direção do olhar e a visão das possibilidades}

A deficiência mental tomada como doença, tal como está até hoje inscrita nos manuais da medicina, também tem uma sintomatologia e uma nosografia, para ser coerente com o modelo médico que ainda a sustenta. $O$ aspecto físico (o corpo do deficiente); sua linguagem (a forma de falar e a coerência); o tempo de seus movimentos e de suas palavras; a atenção (quanto é capaz de acompanhar movimentos ou falas e depois imitar e/ou interpretar); a autonomia para lidar com situações da vida social; a história da gravidez e do parto; as doenças da mãe; a comparação das ações do deficiente com as ações de crianças mais novas (idade mental); os variados tipos de exames que são solicitados; os diagnósticos; os encaminhamentos; o tratamento; a exclusão...

Michel Foucault diz que "no instante mesmo em que ela [a sociedade] diagnostica a doença, exclui o doente" (1991, p. 74).

A exclusão, a denominação de "deficiente", a expressão de morbidez, por um lado dificultam, atrasam (quando não impedem) avanços na construção de conhecimentos dos diferentes campos do saber, tais como a psicologia e a pedagogia; por outro lado, é um convite desafiador para que pesquisadores dessas áreas de conhecimento esclareçam pontos fundamentais sobre o desenvolvimento e a aprendizagem de pessoas com comprometimentos graves. Sem dúvida, ainda há uma estreita ligação das questões da deficiência mental com a medicina e, portanto, com as determinações biológicas das quais a medicina é encarregada. A palavra "deficiência" por si, já delineia a "falta" (no cérebro que comanda o corpo e a mente) e quem descobre o que falta é o médico (neurologista, geneticista...) ou profissionais (psicólogos, fonoaudiólogos...), que aprenderam com a medicina a fazer diagnósticos e prognósticos, classificar e prover o tratamento. No entanto, a ciência não 
é autônoma face às pressões econômicas e sociais; outra questão, portanto, se coloca - a serviço de que sociedade, de que homem, foram construídas as definições de cérebro e de lesão deste cérebro?

Em 1925, Vigotski fundou um laboratório de psicologia para crianças com deficiências. Foi deste laboratório que originou o Instituto Experimental de Defectologia ${ }^{4}$, do qual foi diretor de 1931 a 1934 . Dedicou-se à pesquisa, ensino e programação educativa de crianças com necessidades especiais, na então União Soviética. Suas contribuições foram teóricas, metodológicas, institucionais e clínicas, no campo da deficiência. Entre suas metas estava o desejo de capturar a organização das funções psicológicas e das condutas do deficiente.

As linhas gerais de seu pensamento sobre o desenvolvimento e a aprendizagem dos deficientes foram, na verdade, propostas inovadoras, tanto para o campo das pesquisas quanto para a atuação educacional. Encontramos alguns aspectos deste tipo no núcleo de suas proposições, que ainda hoje são pertinentes. Além de inovadora e pertinente, sua proposta é revolucionária. Perturba profissionais e estudiosos das questões da psicologia e da educação, com sua visão prospectiva do desenvolvimento.

Para ele, não é o defeito que decide o destino das pessoas, mas, sim, as conseqüências sociais desse defeito. A análise dos problemas, segundo Vigotski não deve ser retrospectiva, apenas levando em consideração o passado, mas deve visualizar o futuro da personalidade: é indispensável compreender a vida em seu "movimento eterno", descobrir possibilidades, olhar dialeticamente para os fenômenos humanos: "na teoria da estrutura da personalidade e do caráter, a nova compreensão introduz a perspectiva de futuro" (1989, p. 30).

O problema, a deficiência, o defeito, no lugar de marcar limites, aponta para as capacidades, encontra fontes de força - "que (quantas!) perspectivas tem diante de si o pedagogo quando reconhece que o defeito não é só uma deficiência, uma debilidade, senão também, a fonte da força e das capacidades e que no defeito há algum sentido positivo!" (Ibidem, p. 31).

O que me move na pesquisa é a sua visão das possibilidades de superação da deficiência, com base na força que vem junto com a falta - força criadora da linguagem... Vem a força dos desejos, das fantasias, das tendências psicológicas que criam as possibilidades de vencer as dificuldades.

A perspectiva da força e da positividade da deficiência não é uma questão de fácil compreensão. Não é um conceito transparente. Não se 
trata de uma força individual, que vem "de dentro", inata. Se assim fosse, Vigotski estaria sendo incoerente com sua posição, contrária ao inatismo porque marcadamente histórico-cultural. Esse "impulso" para a superação das dificuldades não é tomado de modo ingênuo, como sendo uma força biológica, própria dos órgãos, que realizariam a compensação do que falta ou do que falha. É possível alguma compreensão da positividade da deficiência com o conceito de compensação proposto por Vigotski, dita de forma explícita quando afirma que qualquer defeito origina estímulos para a formação de compensação, alertando para o fato de que não basta determinar o grau ou a gravidade do defeito, mas o que se deve é encontrar "processos edificadores e equilibradores no desenvolvimento e na conduta da criança" (1989, p. 5).

Não é possível questionar o cotidiano das escolas especiais ou das instituições, ou mesmo dos atendimentos clínicos, se não estivermos convencidos de que a análise que se deve fazer é análise das relações, das interações, do jogo da interlocução. O deficiente não é deficiente por si só, o tempo todo, como uma entidade abstrata e deslocada. A deficiência está contextualizada e marcada pelas condições concretas de vida social.

Vigotski insiste em diversos textos e conferências que o desenvolvimento das funções psicológicas superiores é uma construção coletiva em um primeiro plano, para depois se converter em funções psíquicas da personalidade. "Da discussão nasce o pensamento", diz ele. A linguagem combina sua função de comunicar com a função de fazer pensar, porque a unidade do pensamento é o significado da palavra.

A avaliação clínica/institucional do deficiente mental tem levado à simples constatação das "faltas": sensoriais, motoras, verbais, cognitivas. Dessa forma, a escola especial atua na direção da menor resistência porque se acomoda à deficiência, ajustando seus programas aos requisitos do pensamento chamado concreto (Vigotski, 1997). A proposta da perspectiva histórico-cultural do desenvolvimento aponta para a possibilidade de inverter esse olhar, porque, segundo Vigotski, as funções psíquicas surgidas no processo de interação com as pessoas do meio em que o deficiente está inserido é a esfera que permite a atenuação das conseqüências da deficiência e apresenta maiores chances de influência educativa. O movimento de produzir significado supõe a ação do outro, acontece com o outro e então é possível produzir sentido com o gesto, com o silêncio, com a expressão facial, com a prosódia acompanhando a oralidade, com a lembrança do passado incorporada ao presente. É possível fazer previsões de ação - organização do tempo e do espaço que estão postos na 
cultura. Pensar sobre si, para si e para o outro, dizer as coisas de um certo modo - é a linguagem organizando, comunicando, nomeando, regulando a ação e o pensamento.

\section{Bianca e as esferas do simbólico}

Bianca apresentava dificuldade acentuada de simbolização - de substituir realidades concretas por algo que não pertence ao real concreto, ou seja, por realidades simbólicas. No momento em que a conheci, revelava a existência de processos simbólicos bastante elementares. Durante três anos de intervenção pedagógica, num trabalho sistemático, houve alterações significativas nos processos cognitivos mediados por processos simbólicos: na qualidade da narrativa, na expressão através de gestos significativos, na possibilidade de participar de jogos, nos desenhos, nas trocas de papéis das atividades próprias de dramatização, no uso significativo dos objetos culturais - ou seja, Bianca passou a ocupar lugares discursivos e a viver práticas sociais, também discursivas. Alterações importantes, portanto, na relação entre pensamento e linguagem.

O olhar de Bianca vai se modificando, o riso antes forçado e sem expressão, se altera, como que se amplia. Bianca tem linguagem, mas não dispõe dela com força suficiente para se expandir simbolicamente. O simbólico - lugar de representação do mundo... A avaliação vai sendo composta: quem diz, o quê, para quem, em que situação, com quais propósitos? Era preciso introduzir Bianca nos usos da linguagem... O que é que aquilo quer dizer? Que sentido tem? Por que meios ou processos um enunciado é produzido como tendo sentido? Que significação tem?

\section{Ogesto}

Preocupavam-me os seus movimentos um tanto aleatórios do corpo todo. Ora levantava, ora sentava, ora ia até a porta como se quisesse sair, sem dizer nada... Eu procurava em Bianca os gestos indicativos, o gesto de apontar... o gesto de cumprimentar, dizer adeus... mas não encontrava. O que eu conseguia ver eram indícios de que os objetos culturais não faziam muito sentido para ela - qualquer coisa servia para olhar ou tentar pegar, mas largava com a mesma rapidez com que se aproximava deles. Talvez fosse por isso que seus pais reclamavam que 
"ela não toma banho sem a gente brigar... não lava as mãos, não escova os dentes sozinha, não se limpa após ir ao banheiro...não aprende a ler... fala apenas por monossílabos..."

O corpo de Bianca traduz problemas neurológicos que dificultam sua entrada no mundo das atividades simbólicas. Vista, mesmo de longe, algumas pessoas comentavam que lá estava uma deficiente, uma menina com problemas mentais. Sem a harmonia de movimentos, seu corpo parecia uma palavra mal falada, um texto mal escrito.

Imperativo era organizar a posição do corpo no espaço: organizar-se para ser significado pelos outros, revelando consciência de estar no mundo, diante dos objetos e das pessoas; transformando os objetos e as relações. Os gestos, movimentos com sentido, são ações possíveis de marcar atos corporais de percepção do mundo - do espaço, do tempo, do outro e de si mesmo. São possibilidades de "tocar o mundo" porque de posse do "senso do mundo" para que o corpo não se sinta cego, como comenta Sacks (1997).

Começando a se fazer entender, seus braços e mãos se movimentavam para ajudar a ser interpretada pelo outro. Os movimentos de Bianca foram, aos poucos, se transformando em gestos... Gestos de que Bianca necessitava para dar ciência de seu corpo a si mesma e aos outros. A corporeidade precisava ficar mais expressiva porque mais próxima da corporeidade das moças de sua idade, no seu grupo social.

Não se trata de condicionar ações, pois, como diz Wallon, "o movimento, em sua materialidade aparente, não constitui o ato" (1986, p. 88). Inserção cultural, pertença ao grupo social com seus usos e costumes são práticas discursivas. ${ }^{5}$

O sujeito aparece nas práticas sociais e discursivas e aí aparecem seus gestos, sua atenção, sua memória, seus desejos, o controle da vontade...

Um ano depois de termos iniciado o trabalho com Bianca, ela já realizava gestos indicativos, seus movimentos já eram signos visíveis para o outro; estavam tornando-se significativos, compreensíveis: o simbólico tomando conta do movimento. Se, antes, seu gesto era contido e o riso forçado; os seus braços não davam vida às palavras e ao andar, que era pausado e cambaleante - indícios de que os objetos culturais não se constituíam em realidades simbólicas para ela -, já era possível, agora, notar o impacto do simbólico na motricidade, o impacto do cultural no seu corpo. 
Bianca estava precisando do gesto para dar ciência de seu corpo a si mesma e ao outro. A corporeidade precisava ficar mais expressiva porque mais próxima da corporeidade das moças de sua idade, na sua comunidade. Mas, não foi treinando posturas que tudo aconteceu. Foi porque o papel da linguagem é ser expressiva da corporeidade. A corporeidade traduz sentimentos e consciência. A consciência corporal é fundamental para a linguagem do corpo. Ultrapassando limites, abre possibilidades novas. Bakhtin, numa expressão feliz, parte de uma análise que faz sobre o autor e o herói em sua Estética da criação verbal, diz que "quando abraçamos o corpo, abraçamos também a alma encerrada nesse corpo e que se expressa por ele" (1992b, p. 61). A alma tem expressão no corpo. O corpo do deficiente mental, muitas vezes não consegue revelar ou expressar sua alma porque está caído, desarrumado, desarmônico, inexpressivo, doente; seus movimentos sem sentido não falam ao outro sobre sua alma. É preciso desenvolver a consciência de si para que seja possível expressála nos movimentos do corpo, ao mesmo tempo em que os movimentos do corpo ajudam a tomar consciência de si.

O corpo necessita do outro para lhe atribuir sentido e lhe dar forma. É preciso captar a significação do ato tanto quanto a significação da palavra. O sujeito aparece nas práticas sociais e discursivas e aí aparecem seus gestos, sua atenção, sua memória, seus desejos, o controle de sua vontade.

Conseguir realizar gestos no espaço e no tempo, criando novas configurações, durações e ritmos, constitui a base para muitas aprendizagens, continua dizendo Wallon. Andar com os ombros em equilíbrio - nova música do corpo, nova imagem de si. Carregar o irmãozinho com as duas mãos - garantia de poder carregá-lo e ter com ele uma maior intimidade, pelo contato corpo a corpo. Mocinhas carregam seus irmãos. Bianca não podia fazê-lo sem alguém por perto, carregando junto. Agora pode. A queixa de que Bianca não realizava sozinha as atividades de higiene, muito se relacionavam com os movimentos bastante limitados de seu braço direito. Bianca estava realizando ações cuja semelhança com as ações das pessoas de sua comunidade promove a sua participação nos costumes e modos de lidar com o corpo e os objetos. Sem ligação com o treinamento motor por si mesmo. "O movimento, em sua materialidade aparente, não constitui o ato", diz Wallon (1986, p. 88). Na verdade, um corpo cada vez mais expressivo, porque possível de fazer o outro captar os seus sinais.

O corpo simbólico, que por seus gestos de afeto, indicam o carinho; que por seus gestos de lavar o rosto, representa atitude de higiene 
- pessoa educada, que está sempre limpa, que atrai o outro para perto de si... É captar a significação do ato; é ver finalidade; é controlar a vontade para alcançar a finalidade do ato que é signo.

\section{A narrativa, o gesto e o desenho articulam-se compondo novos saberes}

Nomear o que está à sua frente já acontecia com a mediação do próprio objeto ou cena representada, com uma necessidade cada vez menor de que começássemos a palavra para ela completar. O desenho ganhava forma e sentido no contexto que criávamos ou que nos era imposto. Narrativa, gesto e desenho se articulavam. As histórias da vida e a vida nas histórias... Lidar com objetos não presentes. Imaginar o que já viu, trazer de volta, convertido em fala própria... Aparentemente simples, mas ainda muito difícil para Bianca. No entanto, inegavelmente, fazendo uso da linguagem de forma mais precisa, mais coerente... Ainda que seja na alternância de falas, própria do diálogo. Chama a nossa atenção para uma série de procedimentos que, via de regra, estão negligenciados nas avaliações do deficiente mental.

É possível ir acompanhando a enunciação sendo organizada fora do indivíduo pelas condições extra-orgânicas do meio social, pois "a enunciação enquanto tal é um puro produto da interação social, quer se trate de um ato de fala determinado pela situação imediata ou pelo contexto mais amplo que constitui o conjunto das condições de vida de uma determinada comunidade lingüística", diz Bakhtin (1992b, p. 121).

E, novamente me vejo diante da Psicologia Concreta de Vigotski, para quem a relação das funções psicológicas está, na sua origem, ligada às relações reais entre as pessoas. Sou levada a constatar que está sendo possível identificar, acompanhar, mediar o desenvolvimento cultural de Bianca. Uma pessoa age sobre uma outra necessariamente a partir do exterior, com o auxílio de signos. Uma pessoa age sobre si mesma a partir do exterior e com o auxílio de signos, isto é, de uma maneira social.

As ações humanas são ações significativas, são, portanto, ações simbólicas: criam relações entre os objetos, entre os objetos e as palavras, entre palavra e palavra. As condições de produção dessas ações significativas devem ser compreendidas como relações entre a linguagem, a cognição e a cultura. As nossas ações, minhas e de Bianca, são 
ações sociais, cognitivas, discursivas e pragmáticas. ${ }^{6}$ Incluídas estão as formas de agir sobre o mundo: com o corpo, com os movimentos desse corpo, com o olhar, com as expressões de afeto, amor e ódio, com as palavras, com os silêncios...

Só o gesto não dá conta, a palavra se torna necessária. A linguagem gestual e o processo dialógico não são a mesma coisa, porém têm significação, fazem sentido, dão sentido à relação. A linguagem fica mais completa com os gestos. No início dos atendimentos, eu insistia em ensinar Bianca a fazer gestos para que o outro a entendesse; criei situações diversas para que os gestos fossem absolutamente necessários para uma relação mais significativa: que o jogo acontecesse, que o desenho fosse identificado, que o objeto fosse encontrado, que o outro se sentisse abraçado, que as cartas fossem distribuídas, que o bilhete fosse entregue, que o caderno fosse aberto, que o corpo se movesse harmoniosamente...

Gestos e palavras, carregados de sentido, construídos na interlocução, na relação, no cotidiano que não é dado a priori. Gestos e palavras que são atos de enunciação, de natureza social e que não podem ser explicados a partir das condições apenas biológicas (Bakhtin 1992a).

\section{Ojogo e a dramatização - aspectos do simbólico}

Jogar para brincar, competir, distrair-se, ampliar as possibilidades de estar com pessoas de sua idade que jogam. Entendo que o jogo é uma das esferas do simbólico, é uma das manifestações culturais. Porém, o jogo tem estado presente, na educação infantil e na educação especial, muito mais como material didático do que como uma das formas culturais de entretenimento e lazer.

Meu esforço, no sentido de trazer a discussão sobre a constituição do sujeito simbólico, comprometido pela deficiência mental, inclui o jogo como de suma importância. Para jogar é preciso seguir regras, compartilhar objetivos, fazer das mãos um instrumento cultural dirigido a certos fins. Jogar é brincar, no sentido que dá Vigotski - "fator muito importante do desenvolvimento" (1988, p. 115).

Bianca, que não sabia jogar aos dezessete anos, aprendeu. Passou ser parceira no jogo de baralho, nos jogos com dados: companheira em jogos diversos, que presta atenção, que ri e se diverte, que ganha e que perde. 
Bianca não é mais a mesma jovem deficiente mental. Nem sua deficiência é a mesma. Os problemas já não são os mesmos. Ampliou a consciência do próprio corpo e do corpo do outro. A linguagem, mais desenvolvida, a constitui companheira de conversa, negociadora de sentidos... anuncia e denuncia. Diz de si e dos outros. Dramatiza situações de vida, agindo como se fosse o outro - coloca-se no lugar do outro - expressão do desenvolvimento cognitivo e cultural. Joga, desenha, escreve seu nome, conhece e reconhece números. Usa os instrumentos culturais com mais propriedade escova os dentes para ficar mais bonita e passa baton... penteia-se para que o rapaz de quem gosta a veja bonita. Quer passar creme, perfume. Às vezes chega e diz: "Cheira. Olha como estou cheirosa." "Ganhei um anel..." "Viu minha blusa nova?" "Fui na manicure." "Limpeza de pele... eu fiz." Queixa-se. Reclama: "Minha mãe não quer pôr aparelho no meu dente..." "Meu pai foi embora de casa..." "Não quero falar..." "Me empresta um modess? Esqueci..." "Posso ir no banheiro? Vou lavar a mão... já volto..."

Bianca necessita da palavra do outro, das dicas, das retomadas nos momentos de fracasso de suas expressões... é preciso que esse outro recorra a estratégias para que selecione o caminho mais adequado de produção do discurso. Precisa da mediação efetiva do outro na organização do contexto discursivo, no contexto de aprendizagem, tanto das palavras quanto dos conteúdos para que forme conceitos, generalize, transfira conhecimentos para outras situações - criando e interpretando signos - portanto, criando e interpretando o que é cultural, humano, do sujeito...

A inserção cultural de Bianca passa pela conversão do que é social, do que é do outro, em um "para si". Desenvolvendo-se culturalmente, Bianca transforma as ações do outro e as que realiza com a ajuda do outro, em ações próprias e para o outro.

\section{Práticas educativas:}

\section{a escola especial e a constituição do sujeito simbólico}

A escola especial precisa, antes de mais nada, definir-se quanto à sua concepção de sujeito, de mundo, de sociedade, de deficiência, de eficiência, de desenvolvimento e aprendizagem, para poder conhecer 
mais e melhor sobre as características das crianças e jovens que nela estão e dela esperam um papel crucial no desenvolvimento cognitivo em todas as esferas do simbólico. E isso só é possível a partir de um projeto político-pedagógico que defina, com clareza, seu papel de conhecer, reconhecer e programar a sua tarefa de criação positiva de formas de trabalho, que respondam às particularidades de seus educandos; tanto as particularidades pessoais de gênese biológica quanto as que são construídas na vida social, nas relações concretas de vida de cada um.

Vigotski chama de "novo ponto de vista" o que temos chamado de "um novo olhar" para as limitações e possibilidades dos deficientes; insiste que a validade social é a finalidade da educação. E para ele, o que é cultural é social, os signos são sociais, as ferramentas são sociais, todas as funções superiores desenvolvem-se de modo social, as significações são sociais - a base da estrutura da personalidade é social. A natureza, a gênese e a função da personalidade são sociais. Não podemos pensar a escola fora desse paradigma, fora dessa posição histórico-cultural; caso contrário Bianca e outros muitos deficientes mentais continuarão a ir para a escola só para não ficar à toa, para ocupar o tempo, para dar menos trabalho em casa...

Bianca começou a ser atendida em 1997. Não falava sequer uma palavra sem que alguém começasse a dizê-la. Não permanecia num mesmo tópico por mais de alguns segundos. Seu corpo não fazia parte de seu discurso e não se dava a mostrar aos outros como um corpo de uma jovem - tinha um corpo que costuma ser chamado de "corpo de deficiente", com "jeito de deficiente"... Seus olhos pareciam olhar para o nada. Seus movimentos eram descoordenados e desarmônicos. Não sorria, porque parecia sorrir o tempo todo (e sorriso é só para certas ocasiões).

Os processos de construção de linguagem tomam tempo - "a atividade enunciativa, o processo do dizer, requer tempo para se efetuar" - diz Authier-Revuz (1998, p. 86). No caso de Bianca, demoram mais, pedem maior compreensão de quem está com ela, exigem intencionalidade nas perguntas, na espera pelas respostas, na ajuda para dizer. Authier-Revuz diz mais: as palavras são "porosas" (carregadas de outros discursos); "embutidas" (palavras caleidoscópias); "faltam" (ficam ausentes). É nesse espaço "da não coincidência" que o discurso vai acontecendo e que as esferas do simbólico vão desenvolvendo, ampliando, modificando, ganhando formas e sentidos múltiplos.

Nos testes que pretendem medir a inteligência e nas avaliações psicológicas e pedagógicas que são realizadas nas escolas especiais 
(pude ver e ouvir sobre essas avaliações inúmeras vezes e quem estiver lendo este texto sabe disso), não é considerado, na maioria das vezes, que a reconstrução da linguagem pelos sujeitos deficientes, principalmente por aqueles que apresentam problemas discursivos, insere-se na perspectiva discursiva e mais especialmente nas situações dialógicas em que as pessoas deficientes e as não deficientes estão envolvidas (Coudry, 1986/1988, pp. 58-62). Desconsiderar a elaboração (ou a reelaboração) do discurso é desconsiderar a elaboração (ou reelaboração) das esferas do simbólico, as quais envolvem os sujeitos e sua linguagem, o sujeito e seus gestos, o sujeito e sua inserção cultural.

\section{Considerações finais (muito embora também sejam as iniciais)}

Bianca está cada vez mais "atora"! É possível descobrir a multiplicidade de expressões de vida que Bianca aponta à medida que trilho o caminho teórico-metodológico: a perspectiva histórico-cultural do desenvolvimento humano; o olhar para os detalhes, convite antigo que o paradigma indiciário de Ginzburg (1990; 1998) explicita; a perspectiva enunciativodiscursiva da linguagem que em Maingueneau (1989) é tomada como forma de ação, em que cada ato de fala não se separa das suas condições de produção; a concepção de Bakhtin de que a comunicação verbal está absolutamente entrelaçada a outras formas de comunicação e se faz, num crescendo, "no terreno comum da situação de produção" e que "graças a esse vínculo concreto com a situação, a comunicação verbal é sempre acompanhada por atos sociais de caráter não verbal (...)" (1992a, p. 124), entre os quais Bakhtin aponta os gestos, os rituais, os atos simbólicos.

É possível, diante da descrição de certos acontecimentos, analisar o conjunto das múltiplas transformações e evoluções no desenvolvimento cognitivo e motor de Bianca - justamente porque o motor ganha sentido, ganha estatuto de simbólico, transforma-se em signo para o outro e para si mesmo.

Foi (e é) minha intenção, deixar marcas: com palavras, com fatos, com a vida da Bianca, com os autores que trouxe, com a articulação teórica que fiz, com a introdução de termos e expressões não costumeiras nas discussões sobre deficiência mental, com a detalhada descrição do papel do outro como mediador do uso dos instrumentos culturais em atividades com sentido. Inserção social é isso! O sentido das palavras e 
ações... Quis firmar o papel do outro como fundamental para que aconteça a plasticidade cerebral e, dessa forma aconteça, simultaneamente e articuladamente, o desenvolvimento semiótico, que por sua vez mobiliza funções cerebrais.

Qualquer modificação na Educação Especial, qualquer inovação que se queira precisa radicalizar, isto é, ter o olhar radicalmente voltado para ver o sujeito como alguém que vai se apropriando da cultura e não somente somando hábitos. Deixei de lado, no trabalho com Bianca, as atividades que lembram o funcionamento elementar - do animal, da criança pequena, do pré-escolar...

Foram três anos de encontro semanal com Bianca. Três anos que só aparentemente podem ser delimitados entre março de 1997 e dezembro de 1999. Digo "aparentemente" porque há retomadas constantes do passado, que é constitutivo do sujeito, tanto quanto seu presente e seu futuro. O que Bianca é hoje revela seus anos de vida social antes de nos conhecermos. O que eu sou hoje, por causa de Bianca, transforma meu passado e me abre perspectivas para o futuro.

Alguns aspectos da esfera do simbólico foram privilegiados por mim: a) o gesto - como possibilidade de participar das ações, como expressão da vontade, companheiro da palavra, modo de se fazer entender. A gestualidade limitada e esteriotipada que acompanha a vida de muitos deficientes mentais e é um dos signos da deficiência pode se converter em gestos harmoniosos, indicativos de si mesmo e do mundo que, portanto, podem se converter em novos signos de convivência social com maior aceitabilidade nos grupos sociais de nossa cultura; b) a narrativa - organização no tempo e no espaço, os relatos de fatos da vida, os segredos, os desejos, as histórias ouvidas, vividas ou imaginadas... "A aquisição da narrativa é um indício importante de uma nova relação [do sujeito] com (...) a linguagem. É o momento em que [o sujeito] não depende mais da interpretação/enunciado imediato do outro/interlocutor, em que a progressão do seu discurso já repousa sobre sua própria possibilidade de, interpretando o já dito, lançar o que está por dizer" (De Lemos 1992, p. XIII); c) a dramatização - colocar-se no lugar do outro e de si mesmo, interpretando-se como personagem ou interpretando outro personagem, realizando ações que não realizaria de outra forma. "O que ocorre é uma reprodução da situação real (...). E sendo um aspecto do brincar, "é a criação de uma nova relação entre o campo do significado e o campo da percepção visual - ou seja, entre situações no pensamento e situações reais" (Vygotsky 1988 , p. 109) d) o desenho - que sendo linguagem gráfica e gesto carre- 
ga e materializa o simbólico - significa alguma coisa para si e para o outro. Desenho que acompanha a fala e é permeado por ela: processo decisivo para o desenvolvimento da escrita, segundo Vigotski; e) a participação em jogos - aspecto lúdico que, via de regra não está presente nos meios educativos ou familiares dos deficientes porque, quase sempre, dirigidos a um "pedagogês" que desrespeita e devassa o sujeito. No jogo, operar com o significado dos objetos, do tempo, do espaço, das regras, é um modo semiótico de lidar com o real e o imaginário. Com o jogo, unido ao prazer, ao gosto, ao lúdico, Bianca "aprende a seguir os caminhos mais difíceis, subordinando-se a regras e, por conseguinte, renunciando ao que ela quer, uma vez que a sujeição a regras e a renúncia à ação impulsiva constitui o caminho para o prazer no brinquedo" (idem, 113); f) o uso significativo dos objetos culturais - no lugar do condicionamento para o uso do pente, da escova, do sabonete, do lenço, do lápis, do papel, do correio, dos livros... olhar para as ações humanas em sua absoluta interação com os objetos construídos pela/na cultura. Interação que depende das práticas discursivas e é constituída nelas e por elas, tornando-se, ele mesmo, o uso dos objetos, uma prática discursiva. Interpretar e produzir signos - eis o processo de simbolização. O uso dos objetos não são fins em si mesmos. Os hábitos de higiene não existem desvinculados, desarticulados, isolados, à parte da vida social. Os modos de se comunicar para pedir, agradecer, negar, afirmar, prometer, desculpar-se também não. Atividades isoladas lembram um funcionamento elementar, mais próximo da visão zoológica de homem e de funções psíquicas.

Vigotski relaciona pensamento e linguagem não havendo, para ele, possibilidade de desenvolvimento cognitivo fora da linguagem e nem linguagem sem a mediação que acontece nos processos interativos. A linguagem é o principal mediador, necessariamente simbólico, entre o mundo cultural e o biológico.

O caráter semiótico do desenvolvimento humano, se tomado a sério dos estudos de Vigotski, faz a diferença: o que é especificamente humano, a atividade específica da linguagem, é que providencia os instrumentos auxiliares para a solução dos problemas, é que direciona a vontade, planeja a ação, controla e regula o comportamento. As ações humanas, mais do que serem ações condicionadas por estímulos externos, são ações mediadas por signos. As práticas culturais são práticas discursivas e a verdadeira essência do comportamento humano complexo é a atividade simbólica com função organizadora específica que penetra o uso dos instrumentos e faz nascer novos modos de ser. 
O conceito marxista de uma psicologia humana historicamente determinada é o pano de fundo para a hipótese fundamental de que cognição e linguagem são socialmente formadas e culturalmente constituídas, nas relações concretas de vida. A linguagem, entendida como trabalho constitutivo exclui, de modo radical, a possibilidade de que o desenvolvimento cognitivo possa acontecer desvinculado da linguagem do outro e dos signos; impossível pensar desenvolvimento cognitivo fora da cultura e da linguagem; impossível pensar isso tudo sem o papel fundante dos processos de significação. Processos de significação que se criam entre as pessoas, no meio social. Cada objeto, cada ação, cada palavra, cada aprendizagem adquire, segundo Bakhtin "significação interindividual", ou seja, "o que faz da palavra uma palavra é a sua significação. O que faz da atividade psíquica uma atividade psíquica é, da mesma forma, sua significação" (Bakhtin, 1992a, p. 49).

A atividade mental revela-se no terreno semiótico.

\section{Notas}

1. A linguagem, por meio de seu papel mediador, organiza a relação do interpretante (possibilidade de significar) entre atividade cognitiva e discurso. A linguagem aparece e mostra, dando visibilidade ao que está ou não alterado. $\mathrm{Na}$ linguagem em exercício, é possível ver o que falta ou o que excede e como os processos de significação são elaborados pelos interlocutores, nas diferentes instâncias nas quais os sujeitos se expõem (Coudry 1997).

2. É importante ressaltar a discussão que Smolka faz sobre a concepção de linguagem como instrumento. Reconhece que Vygotsky deixa margem para diferentes interpretações, muitas delas contraditórias. Porém, a autora explica que "as elaborações de Vygotsky vão além da questão instrumental. Anunciam outras possiblidades de se conceber a linguagem, o que traz para o centro das discussões a questão do seu caráter constitutivo" (1995, p:12).

3. Os termos "apropriação" e "domínio" parecem ser mais adequados do que o termo "internalização" usado por Vigotski, mesmo que ainda constituam problema conceitual para a perspectiva histórico-cultural da psicologia. A preocupação dos autores é que no uso das palavras possamos deixar explicitado que os contrários co-existem, ou seja, que não se trata de separar o que está dentro do que está fora.

4. Vigotski diz que a defectologia, para ele, é uma ciência que tem como objeto especial de estudo os processos de desenvolvimento infantil com uma quantidade quase ilimitada dos seus diferentes tipos. Desta forma, deve estabelecer 
os ciclos, as transformações deste desenvolvimento, suas desproporções, revelando as leis de sua diversidade.

5. Maingueneau (1989) fala de prática discursiva para designar a reversibilidade entre as duas faces do discurso: a social e a textual. A prática discursiva integra a formação discursiva (um conceito de Michel Foucault) e o grupo ou grupos no interior dos quais são gerados os textos que dependem da formação discursiva (comunidade discursiva) (p. 56).

6. De acordo com Coudry (1988), a língua é resultado de trabalho coletivo, histórico e cultural de onde nascem os recursos expressivos próprios (dimensão sintática); o sistema de referência dessa língua é um sistema cultural do qual partilha uma determinada comunidade (dimensão semântica) e, a linguagem é usada em situações concretas e vai além do estritamente dito (dimensão pragmática).

Encaminhado para publicação em maio de 2000

\section{Educative practices: \\ Perspectives that open to the especial education.}

ABSTRACT: This text objective is to register reflections that permits a major understanding of the symbolization concept to introduce the issue of the symbolic subject constitution, implicated by mental deficiency. The reflections pass by meetings with different authors, from different areas of knowledge having the intention of making the choice of the historical-cultural perspectives with the one that best answers to the interrogations about the human being capable of giving meaning to the world, even being stopped by organic problems. The Vigotski and Bakhtin's contributions are fundamental. They conceive man as a being that signifies and constitutes himself in the concrete relations of life.

\section{Bibliografia}

ALTHIER-REVUZ, J. Palavras incertas. Campinas: Editora da Unicamp, 1998.

BAKHTIN, M. (Volochinov) Marxismo e Filosofia da Linguagem. S.Paulo: Hucitec, 1992a. . Estética da Criação Verbal. São Paulo: Martins Fontes, 1992b.

CANGUILHEM, G. O normal e o patológico. R.J.: Forense Universitária, 1995. 
COUDRY, M. I. Hadler. Diário de Narciso - discurso e afasia. São Paulo: Martins Fontes, 1988. [Original de 1986]

. "Língua, discurso e a lógica da linguagem patológica". In Cadernos da F. F. C./ Unesp., vol. 6, no 2. Marília: Unesp, 1997.

DE LEMOS, C. T. G. "Prefácio". In PERRONI, M. C. Desenvolvimento do discurso narrativo. São Paulo: Martins Fontes, 1992.

FOUCAULT, M. Doença Mental e Psicologia. Rio de Janeiro: Tempo Brasileiro, 1991.

GINZBURG, C. Mitos, Emblemas, Sinais - morfologia e história. São Paulo: Companhia das Letras, 1990.

. O queijo e os vermes - o cotidiano e as idéias de um moleiro perseguido pela Inquisição. São Paulo: Companhia das Letras, 1998.

LEONTIEV, A. "O homem e a cultura". In ENGELS, GEERTZ, BAUMAN, LEONTIEV \& MARCARIAN. O homem e a cultura. Lisboa: Iniciativas Editoriais, 1976.

MAINGUENEAU, D. Novas tendências em Análise do Discurso. Campinas: Pontes, 1989.

MARX, K. O capital. Livro 1, volume 1. Rio de Janeiro: Bertrand Brasil, 1989.

PINO, A. "A criança, seu meio e a comunicação - perspectiva sócio-histórica do desenvolvimento". Revista da Associação Brasileira de Psicopedagogia, vol. 12, no 26, 1993a, pp. 9-15.

SACKS, O. O homem que confundiu sua mulher com um chapéu. São Paulo: Companhia das Letras, 1997.

SMOLKA, A. L. B. "A concepção de linguagem como instrumento: um questionamento sobre práticas discursivas e educação formal". In: S.B.P.: Temas em Psicologia. Cognição e linguagem - a questão da integração do deficiente; № 2, 1995.

VYGOTSKY, L. S. "Concrete Human Psycology", Soviet Psychology, v. XXVII, n. 2., 1986, pp. 53-77. (Tradução para o português de Enid Abreu Dobránszky, 1989).

. Obras Escogidas II. Madrid: Visor, 1993.

. A formação social da mente. São Paulo: Martins Fontes, 1988. 
. "Fundamentos de Defectología". Obras Completas, Tomo V. Habana: Editorial Pueblo e Educacion, 1989.

Fontes, 1996.

WALLON, H. A evolução psicológica da criança. Rio de Janeiro: Andes, s/d.

WALLON, Henri "Do ato ao pensamento". In WEREBE, M. J. G. \& NADELBRULFERT J. (orgs.). Henri Wallon. Psicologia. Coleção Grandes Cientistas Sociais. São Paulo: Ática, 1986. 